A N N A LES

UNIVERSITATIS MARIAE CURIE-SKŁODOWSKA

LUBLIN - POLONIA

VOL. LXVI, 1, 2

SECTIO AA

2011

\title{
Transformation of alumina supported nickel catalysts during hydrodechlorination of 1,2-dichloroethane*
}

\author{
W. Juszczyk ${ }^{1}$ and Z. Karpiński ${ }^{1,2,3}$ \\ ${ }^{1}$ Institute of Physical Chemistry of PAS, ul. Kasprzaka 44/52, \\ 01-224 Warszawa, Poland \\ ${ }^{2}$ Faculty of Mathematics and Natural Sciences - School of Science, Cardinal \\ Stefan Wyszyński University, ul. Wóycickiego 1/3, 01-938 Warszawa, Poland \\ ${ }^{3}$ Corresponding author, tel. +48-22-343-33-56; fax: +48-22-343-33-33; \\ e-mail: $z k @ i c h f . e d u . p l$
}

\begin{abstract}
Our previous work with Sibunit carbon supported nickel catalysts investigated in the reaction of 1,2-dichloroethane hydrodechlorination showed the transformation of nickel to an fcc $\mathrm{NiC}_{\mathrm{x}}$ solution and/or even to an hcp $\mathrm{Ni}_{3} \mathrm{C}$ carbide phase during reaction. Carbon entering to nickel was considered to originate from the organic molecule, not from the carbon support. To substantiate this interpretation we decided to carry out the title reaction in the presence of alumina supported nickel catalysts. Hydrodechlorination of 1,2-dichloroethane performed on differently metal loaded $\mathrm{Ni} / \mathrm{Al}_{2} \mathrm{O}_{3}$ catalysts resulted in a massive carbiding of nickel, leading to the $\mathrm{Ni}_{3} \mathrm{C}$ carbide phase. This effect was better marked for the catalysts with a higher Ni loading ( $\geq 2$ wt. $\%$ ). However, for very high Ni loading (20 wt.\%) characterized by bigger metal crystallites $(\sim 30 \mathrm{~nm})$, only a portion of Ni was carbided.
\end{abstract}

\section{INTRODUCTION}

Catalytic hydrodechlorination $(\mathrm{HdCl})$ offers an exceptional advantage over all oxidative (noncatalytic and catalytic) methods of destruction of harmful chlorinated compounds. This is because the carbon skeleton of a chlorine-

*This article is dedicated to Professor Dobiesław Nazimek on the occasion of his $65^{\text {th }}$ birthday 
containing organic molecule is not irreversibly lost (i.e. not converted to $\mathrm{CO}_{2}$ ), but several useful and less harmful products could be achieved in effect of catalytic transformation. However, search for active, selective and durable catalysts is still on. Nickel, in addition to platinum and palladium, is regarded as an efficient hydrodechlorination catalyst [1-9]. In the case of vicinal dichlorocarbons, $\mathrm{Ni}$ is even better than $\mathrm{Pt}$ and $\mathrm{Pd}$, because in its presence the hydrodechlorination products are unsaturated compounds, more valuable than their saturated analogs.

There are different opinions as to the fate of nickel (active) phase during $\mathrm{HdCl}$ reactions. Some recent papers occasionally report a (partial) transformation of the fcc Ni phase into either hcp $\alpha$-Ni [2,3] or hcp $\mathrm{Ni}_{3} \mathrm{C}$ phase [10], or no $\mathrm{Ni}$ phase change [11,12] during $\mathrm{HdCl}$ reactions. Our recent work on $\mathrm{HdCl}$ of 1,2-dichloroethane (DCE) on Sibunit carbon nickel catalyst showed a massive transformation of nickel to nickel carbide phases (fcc $\mathrm{NiC}_{\mathrm{x}}$ and hcp $\mathrm{Ni}_{3} \mathrm{C}$ ), [13-15]. Carbon incorporated into $\mathrm{Ni}$ was considered to originate from the organic molecule. To confirm this hypothesis, the present hydrodechlorination study was carried out on alumina supported Ni catalysts.

\section{MATERIAL AND METHODS}

The 1, 2, 5 and 20 wt.\% metal-loaded nickel catalysts were prepared by incipient wetness impregnation of $\gamma$-alumina from Sasol (150-200 mesh, specific surface area $\left.196 \mathrm{~m}^{2} / \mathrm{g}\right)$. Nickel (II) chloride $\left(\mathrm{NiCl}_{2} * 6 \mathrm{H}_{2} \mathrm{O}\right.$, of analytical purity from POCh, Gliwice, Poland) was used in catalyst preparation. During impregnation and preliminary drying with infrared lamps, a proper mixing was assured by the rotary motion of a beaker containing the catalyst precursor. Then, the solid was further dried overnight at an air oven at $90^{\circ} \mathrm{C}$ and stored in a desiccator.

Crystallite size of $\mathrm{Ni}$ in the catalysts was assessed from X-ray diffraction (XRD). XRD experiments were performed on a Siemens D5000 diffractometer using Ni-filtered $\mathrm{CuK}_{\alpha}$ radiation. Several samples of $\mathrm{Ni} / \mathrm{Al}_{2} \mathrm{O}_{3}$ catalysts (reduced and after reaction) were scanned by a step-by-step technique, at $2 \theta$ intervals of $0.02^{\circ}$. The catalytic conversion of DCE was investigated using a glass flow reaction system [13-15]. After reduction at $500^{\circ} \mathrm{C}$ for $3 \mathrm{~h}$ in $10 \% \mathrm{H}_{2} / \mathrm{Ar}$ flow $(25$ $\mathrm{cm}^{3} / \mathrm{min}$ ), the catalysts were investigated in the reaction of DCE with hydrogen $\left(1: 1\right.$ ratio) at $230^{\circ} \mathrm{C}$. Total flow of the reaction mixture was $41.1 \mathrm{~cm}^{3} / \mathrm{min}\left(\mathrm{H}_{2}\right.$ : $1.15 \mathrm{~cm}^{3} / \min$, DCE: $1.15 \mathrm{~cm}^{3} / \mathrm{min}$, Ar: $38.8 \mathrm{~cm}^{3} / \mathrm{min}$ ). The mass of the catalyst used ranged between 0.1 and $0.4 \mathrm{~g}$, depending on the metal loading, in order to not exceed conversion levels beyond $10 \%$. In all kinetic runs, the activities of all 
catalysts declined with time on stream. A typical run lasted ca. $24 \mathrm{~h}$. The reaction was followed by gas chromatography (HP 5890 series II with FID, a 5\% Fluorcol/Carbopack B column (10 ft) from Supelco).

\section{RESULTS AND DISCUSSION}

Crystallite sizes of nickel assessed from XRD (using the Scherrer formula) are shown in Table 1.

Tab. 1. Ni crystallite sizes in alumina supported catalysts after reduction at $500^{\circ} \mathrm{C}$ for $3 \mathrm{~h}$.

\begin{tabular}{|c|c|c|c|}
\hline $\begin{array}{l}\text { Ni loading, } \\
\text { wt. } \%\end{array}$ & Reflection & $\begin{array}{c}\text { Ni crystallite size } \mathrm{a}^{\mathrm{a}} \text { nm } \\
\end{array}$ & $\begin{array}{c}\text { Average Ni crystallite } \\
\text { size }^{\mathrm{b}}, \mathrm{nm}\end{array}$ \\
\hline \multirow{3}{*}{1} & 111 & 14.4 & \multirow{3}{*}{12.6} \\
\hline & 200 & 6.1 & \\
\hline & 220 & 17.2 & \\
\hline \multirow{3}{*}{2} & 111 & 20.0 & \multirow{3}{*}{17.1} \\
\hline & 200 & 13.5 & \\
\hline & 220 & 17.9 & \\
\hline \multirow{3}{*}{5} & 110 & 20.7 & \multirow{3}{*}{15.6} \\
\hline & 200 & 13.1 & \\
\hline & 220 & 13.0 & \\
\hline \multirow{3}{*}{20} & 111 & 36.5 & \multirow{3}{*}{29.7} \\
\hline & 200 & 28.6 & \\
\hline & 220 & 23.9 & \\
\hline
\end{tabular}

${ }^{\text {a }}$ From the Scherrer formula.

${ }^{\mathrm{b}}$ From three basic XRD reflections (111, 200 and 220) of Ni.

It is seen that the three less loaded $\mathrm{Ni}$ catalysts (1,2 and 5 wt.\%) were characterized by roughly similar metal particles, whereas the most Ni loaded catalyst (20 wt.\%) had much larger Ni crystallites. This difference will have an effect on the extent of phase transformations during hydrodechlorination (discussed later).

Figure 1 shows the $\mathrm{X}$-ray diffractogrammes of $1 \mathrm{wt} \% \mathrm{Ni} / \mathrm{Al}_{2} \mathrm{O}_{3}$ catalyst subjected to reduction at $500^{\circ} \mathrm{C}$ and reaction at $230^{\circ} \mathrm{C}$. At first glance, both diffractogrammes are very similar, suggesting no big change in the structure of catalyst caused by reaction. The situation is complicated by overlapping the main $\mathrm{Ni}$ reflection (111) with the (400) reflection from alumina. However, the absence of (200) reflection of $\mathrm{Ni}$ at $2 \theta \approx 51.8^{\circ}$ in the profile of used catalyst suggests that the fcc phase of Ni has been transformed into another species. Somewhat better developed XRD reflection at $2 \theta \approx 39^{\circ}$ and a slight irregularity in the course of descending branch at $2 \theta \approx 41^{\circ}$ would result from the contribution of hcp phase of 
$\mathrm{Ni}_{3} \mathrm{C}$. However, at so low Ni loading, the overall XRD picture is dominated by reflections from the alumina support.

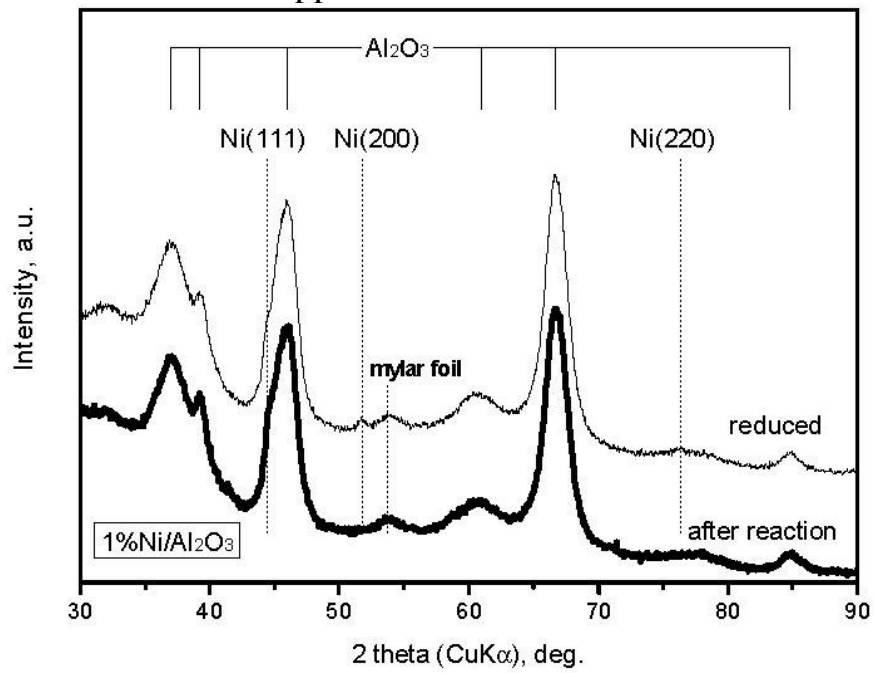

Fig. 1. Comparison of XRD profiles of $1 \mathrm{wt} . \% \mathrm{Ni} / \mathrm{Al}_{2} \mathrm{O}_{3}$ catalysts: reduced (thin line) and subjected to $\mathrm{HdCl}$ of 1,2-dichloroethane (thick line). Dotted lines indicate basic XRD reflections of $\mathrm{Ni}$ (fcc phase) and solid lines indicate positions of basic XRD reflections of $\gamma$-alumina.

Much better insight into the problem of $\mathrm{Ni}$ transformation during $\mathrm{HdCl}$ follows from studying the $\mathrm{Ni} / \mathrm{Al}_{2} \mathrm{O}_{3}$ catalysts characterized by a higher metal loading (2, 5 and $20 \mathrm{wt} . \%)$. A complete disappearance of the (200) reflection of $\mathrm{Ni}$ observed for 2 and 5 wt. $\%$ Ni/ $/ \mathrm{Al}_{2} \mathrm{O}_{3}$ catalysts (Figs. 2 and 3) is now accompanied by a distinct development of XRD reflections characteristic of $\mathrm{Ni}_{3} \mathrm{C}$ (hcp) phase (represented by stars in Figs. 2, 3 and 4). Partial carbiding leading to the formation of the fcc $\mathrm{NiC}_{\mathrm{x}}$ phase detected in our previous studies with $\mathrm{Ni} / \mathrm{C}$ catalysts [13-15] is not observed here. However, in the present case a serious overlap of the (111) reflection of $\mathrm{Ni}$ with the (400) reflection from alumina makes such observation very difficult. Much less intense (200) and (220) Ni reflections observed for the reduced catalysts practically disappear after $\mathrm{HdCl}$ (Figs. 2 and 3), so it is impossible to make speculations about their shift towards lower diffraction angles, which would be suggestive of some presence of carbided fcc $\mathrm{NiC}_{\mathrm{x}}$ phase.

A rough comparison of peak widths in reduced catalysts (Ni reflections) and after reaction $\left(\mathrm{Ni}_{3} \mathrm{C}\right.$ reflections) suggests no metal sintering caused by hydrodechlorination. Also an apparent absence of XRD reflections characteristic of nickel dichloride indicates that bulk chloriding of nickel does not occur during hydrodechlorination of 1,2-dichloroethane at $230^{\circ} \mathrm{C}$. 


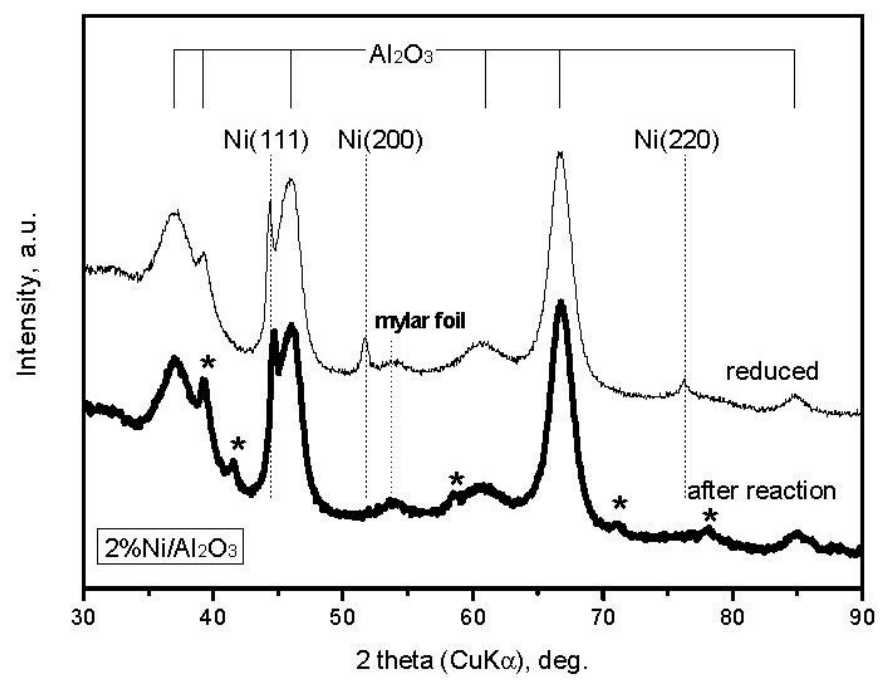

Fig. 2. Comparison of XRD profiles of $2 \mathrm{wt} . \% \mathrm{Ni} / \mathrm{Al}_{2} \mathrm{O}_{3}$ catalysts: reduced (thin line) and subjected to $\mathrm{HdCl}$ of 1,2-dichloroethane (thick line). Dotted lines indicate basic XRD reflections of $\mathrm{Ni}$ (fcc phase) and solid lines indicate positions of basic XRD reflections of $\gamma$-alumina. Stars symbolize positions of XRD reflections of $\mathrm{Ni}_{3} \mathrm{C}$ (hcp).

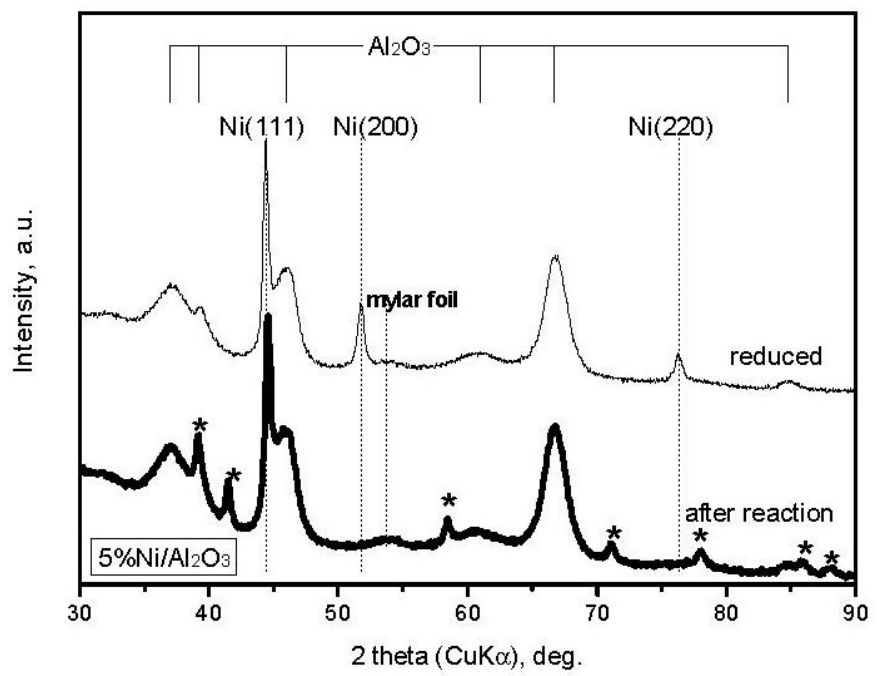

Fig. 3. Comparison of XRD profiles of $5 \mathrm{wt} \% \mathrm{Ni} / \mathrm{Al}_{2} \mathrm{O}_{3}$ catalysts: reduced (thin line) and subjected to $\mathrm{HdCl}$ of 1,2-dichloroethane (thick line). Dotted lines indicate basic XRD reflections of $\mathrm{Ni}$ (fcc phase) and solid lines indicate positions of basic XRD reflections of $\gamma$-alumina. Stars symbolize positions of XRD reflections of $\mathrm{Ni}_{3} \mathrm{C}$ (hcp). 
Interestingly, Figure 4 representing the behavior of 20 wt.\% Ni/ $\mathrm{Al}_{2} \mathrm{O}_{3}$ catalyst, shows that a considerable part of nickel is not transformed into $\mathrm{Ni}_{3} \mathrm{C}$ after hydrodechlorination. Such conclusion follows from the presence of (200) and (220) Ni reflections in used catalysts. In addition, $\mathrm{HdCl}$ does not result in shift of these reflections towards lower diffraction angles, which would be suggestive of some carbon incorporation. Therefore, it appears that this "unaffected" nickel material represents the interior of metal crystallites, not reached by carbon species during reaction. It is recalled that the $20 \mathrm{wt} \%$ $\mathrm{Ni} / \mathrm{Al}_{2} \mathrm{O}_{3}$ catalyst was characterized by very big metal crystalites $(\sim 30 \mathrm{~nm}$ in size). Apparently, such large Ni crystallites are not easily carbided due to limited diffusion of carbon at $230^{\circ} \mathrm{C}$.

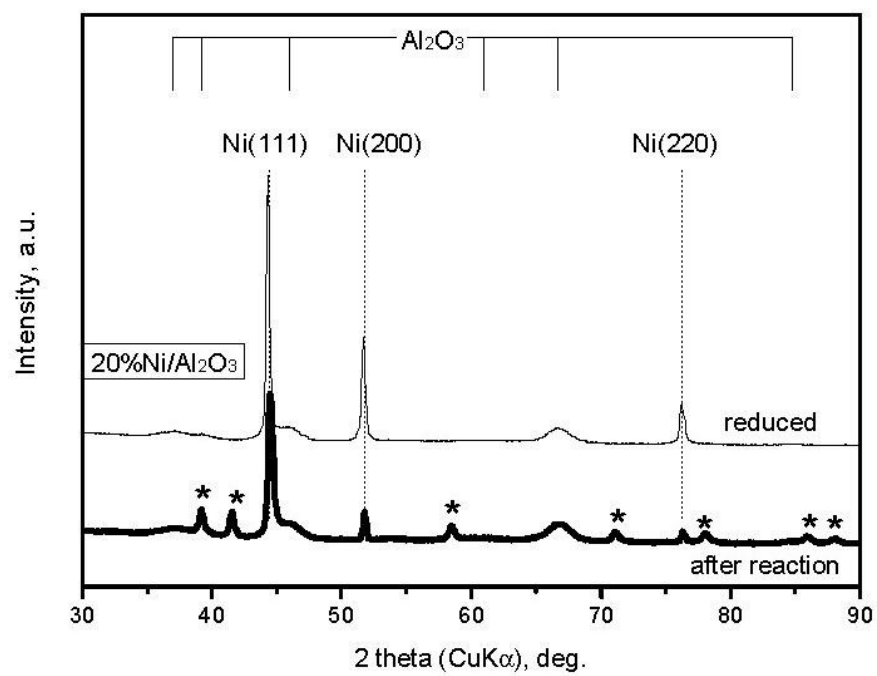

Fig. 4. Comparison of XRD profiles of 20 wt. $\% \mathrm{Ni} / \mathrm{Al}_{2} \mathrm{O}_{3}$ catalysts: reduced (thin line) and subjected to $\mathrm{HdCl}$ of 1,2-dichloroethane (thick line). Dotted lines indicate basic XRD reflections of $\mathrm{Ni}$ (fcc phase) and solid lines indicate positions of basic XRD reflections of $\gamma$-alumina. Stars symbolize positions of XRD reflections of $\mathrm{Ni}_{3} \mathrm{C}$ (hcp).

\section{CONCLUSIONS}

Hydrodechlorination of 1,2-dichloroethane studied on differently metal loaded $\mathrm{Ni} / \mathrm{Al}_{2} \mathrm{O}_{3}$ catalysts led to a massive carbiding of nickel dectected by formation of the $\mathrm{Ni}_{3} \mathrm{C}$ carbide phase. Carbon entering nickel bulk originated from the organic molecule. Unexpectedly, the presence of previously seen partly carbided $\mathrm{Ni}$ fcc phase $\left(\mathrm{NiC}_{\mathrm{x}}\right)$ was not confirmed. Carbiding was much better 
detected for the catalysts with a higher Ni loading ( $\geq 2 \mathrm{wt} . \%)$. However, for very high Ni loading (20 wt.\%) characterized by bigger metal crystallites, only a portion of $\mathrm{Ni}$ was carbided.

Acknowledgments. This work was supported by the Polish Ministry of Science and Higher Education within Research Project N N204 161636.

\section{REFERENCES}

[1] Y. Anju, I. Mochida, H. Yamamoto, A. Kato, T. Seiyama, Bull. Chem. Soc. Japan, 452319 (1972).

[2] Y. H. Choi, W. Y. Lee, Catal. Lett., 67155 (2000).

[3] Y. H. Choi, W. Y. Lee, J. Mol. Catal. A, 174193 (2001).

[4] P. Kim, Y. Kim, H. Kim, I. K. Song, J. Yi, J. Mol. Catal. A, 21987 (2004).

[5] Y. Park, T. Kang, J. Lee, P. Kim, H. Kim, J. Yi, Catal. Today, 97195 (2004).

[6] V. V. Shapovalov, A. Yu. Ivanov, V. K. Shiryaev, Zh. Prikl. Khim., 69513 (1996).

[7] V. V. Shapovalov, A. Yu. Ivanov, V. K. Shiryaev, Zh. Fiz. Khim., 721326 (1998).

[8] W. Ueda, S. Tomioka, Y. Morikawa, M. Sudo, T. Ikawa, Chem. Lett., 879 (1989).

[9] A. Morato, C. Alonso, F. Medina, P. Salagre, J.E. Sueiras, R. Terrado, A. Giralt, Appl. Catal. B, 23175 (1999).

[10] K. V. Murthy, P. M. Patterson, G. Jacobs, B. H. Davis, M. A. Keane, J. Catal., 22374 (2004).

[11] N. Lingaiah, Md. A. Uddin, A. Muto, T. Iwamoto, Y. Sakata, Y. Kusano, J. Mol. Catal. A, 161157 (2000).

[12] G. Pina, C. Louis, M. A. Keane, Phys. Chem. Chem. Phys., 51924 (2003).

[13] A. Śrębowata, W. Juszczyk, Z. Kaszkur, J. W. Sobczak, L. Kępiński, Z. Karpiński, Appl. Catal. A, 319181 (2007).

[14] A. Śrębowata, W. Juszczyk, Z. Kaszkur, Z. Karpiński, Catal. Today, 12428 (2007).

[15] A. Śrębowata, I. Stefanowicz-Pięta, W. Juszczyk, Z. Karpiński, Polish J. Chem., 811521 (2007).

\section{CURRICULA VITAE}

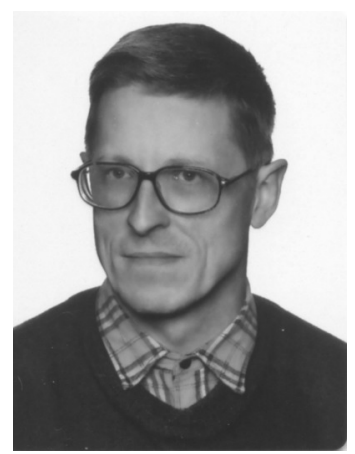

Wojciech Juszczyk. Born in Warsaw in 1955. Graduated from Warsaw University of Technology (1979), specializing in chemical technology. Received his $\mathrm{PhD}$ degree (1995) in physical chemistry from the Institute of Physical Chemistry of PAS (IPC PAS) in Warsaw, where he works as a specialist in the Department of Catalysis on Metals. Current research areas: testing supported mono- and bimetallic catalysts in catalytic conversion of chloroorganic compounds, catalyst characterization using chemisorption and X-ray diffraction techniques. 


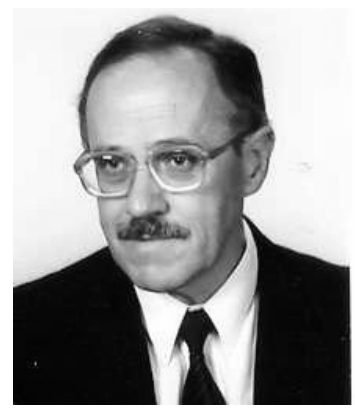

Zbigniew Karpiński. Born in Lwów in 1944. Graduated from Warsaw University of Technology (1966), specializing in chemical engineering. He received his $\mathrm{PhD}$ and $\mathrm{DSc}$ degrees in physical chemistry (1972 and 1990, respectively) from the Institute of Physical Chemistry of PAS (IPC PAS) in Warsaw, where he is the department head (Catalysis on Metals) from 1992. He is an ordinary professor at IPC PAS (from 1998) and also at the Cardinal Stefan Wyszyński University, Faculty of Mathematics and Natural Sciences - School od Science (from 2001). He works on various topics associated with supported mono- and bimetallic catalysts, especially for their application in environmental protection (over 130 scientific publications). 